\title{
Santiago Melón Fernández
}

\author{
Álvaro Ruiz de la Peña Solar
}

El pasado viernes, día 16 de noviembre, a las seis y cuarto de la tarde, fallecía en el Centro Médico de Oviedo el historiador y profesor universitario Santiago Melón Fernández. A esa hora asistía yo a las últimas comunicaciones presentadas en el Congreso de Clarín, poco antes de cerrarse brillantemente después de una intensa semana de sesiones. Así que al tiempo que declinaban las exposiciones académicas declinaba también, definitivamente, la vida de otro ovetense ilustre, cien años después de la desaparición del gran Leopoldo Alas.

Mi relación personal con Santiago se remonta a los años sesenta. Yo iniciaba los estudios universitarios en la Facultad de Filosofía y Letras y él estrenaba, después de ganar los premios extraordinarios de licenciatura y doctorado, una cátedra de Instituto que le llevaría a Ciudad Rodrigo y posteriormente a Vigo, para recalar por fin en Asturias, en el Instituto femenino «Menéndez Pidal» de Avilés. Allí volvería a encontrarme con él en el curso 1971-1972. Ocupaba un cargo directivo en el centro (creo que la jefatura de estudios) y gozaba de una popularidad y un prestigio enormes entre las alumnas, que disfrutaban con sus magníficas clases de Historia de España y de aquel sentido del humor que conservó hasta los últimos tiempos de su vida. Recuerdo que en una ocasión le pedí por favor que, cuando explicara el siglo XIX, me dejase asistir a alguna clase. No puso inconveniente alguno y cuando llegó el momento me lo recordó. «Mañana voy a hablar del problema sucesorio y de la primera guerra carlista, así que te llegó la hora», me dijo. Al día siguiente entré en su aula, me senté discretamente en 
una de las últimas filas de pupitres vacías y me dispuse a escuchar con enorme curiosidad a aquel joven maestro de treinta años. Quedé, lo digo sin hipérbole, hipnotizado, fascinado por sus conocimientos (hablaba sin papeles, notas ni libros) sobre aquel tiempo, uno de los más enrevesados y convulsos de toda la historia de España, verdadera piedra de toque para la capacidad docente de un profesor de historia. Y no sólo por los conocimientos, claro, sino por la forma de conducirlos a través del discurso, salpicado de ironía crítica, de comentarios y revelaciones inteligentes sobre hechos o figuras de la época, de excursiones sutiles al campo de la literatura, la religión o la economía del período, de admirables interpretaciones sobre la situación contemporánea europea...

Era Santiago un profesor de historia excepcional, dotado de una amplísima cultura y con una rigurosa formación intelectual en la que habían tenido mucho que ver los clásicos del pensamiento racionalista y regeneracionista de finales del siglo XIX y, también, su perspicaz conocimiento de la historiografía marxista. Precisamente, en virtud de su formación académica, que vino a completar la influencia marcadamente liberal que le imprimió su padre, el psiquiatra Santiago Melón Ruiz de Gordejuela, Santiago no comulgó jamás con el estado de cosas impuesto en España durante el régimen dictatorial de Franco. Admiraba demasiado a muchas de las figuras políticas de la II República (Azaña, Marcelino Domingo, Besteiro, Zugazagoitia, Negrín, «al que nunca se le ha hecho justicia», solía decir, y otros muchos que sería prolijo recordar) para que pudiera sentir simpatía o compasión por aquel sistema autoritario, levítico e intelectualmente castrador que hubimos de padecer hasta la reinstauración de las libertades democráticas.

A partir de 1973 nuestras vidas se bifurcaron unos años. Él continuaría en Avilés hasta el curso 1979-1980 y yo recompuse mi actividad laboral entrando a trabajar en el antiguo Centro de Estudios del Siglo XVIII, que dirigía José M. Caso González.

En 1980 Santiago se incorporó a la cátedra de Historia Económica en la Escuela Universitaria de Estudios Empresariales de Oviedo. Podría decirse aquello de que nunca es tarde si la dicha es buena. Siempre he pensado que la vida ha sido injusta con muchos catedráticos y profesores de instituto que, por mor de las circunstancias, han desarrollado su vida docente en los institutos de enseñanza secundaria, pudiendo hacerlo por competencia y dedicación, en otros centros universitarios en lo que su palabra pudiera tener una más inmediata utilidad. Afortunadamente, la universidad acabó rescatando a Santiago para la docencia y éste pudo volcar durante más de veinte años toda su capacidad y conocimientos en la enseñanza de las materias de historia económica que se le habían asignado.

En la década de los ochenta compartí con Santiago las labores editoriales en el consejo de redacción de la revista Ástura, junto a otros queridos amigos 
de nuestra universidad. Su aportación (durante los años 1985, 1986 y 1987) no se limitó a enriquecer debates de esa comisión redactora sobre la línea editorial de la publicación, sobre la calidad de los trabajos recibidos para su publicación u otros temas relacionados con la vida cultural asturiana, sino que se tradujo en una gavilla de notas, reseñas y artículos que enriquecen la breve colección de la revista, añadiendo el plus de interés, rigor y amenidad que ésta intentaba en cada número.

Santiago nunca fue un investigador de producción escrita abundante; jamás se sintió urgido por cuestiones curriculares y su falta de ambición personal - unida, todo hay que decirlo, a una actitud desdeñosa hacia determinados prestigios académicos - hizo que su bibliografía no rebase hoy la treintena de textos salidos de su pluma. No quiso, o no encontró el momento o la ocasión de escribir el gran libro que le hubiera dado renombre general, pero en esa treintena de artículos, pequeños ensayos y otros escritos de variado carácter dejó siempre impreso su enorme talento analítico y su amplísima cultura de historiador comprometido con la verdad.

De los últimos tiempos de la vida de Santiago no quiero hablar porque, con una salud cada vez más declinante, pertenecen casi por entero al ámbito de lo privado. Con él me reí, discutí, compartí irritaciones de distinto tipo, viví, en definitiva, la hora del mundo, hablando de lo divino y de lo humano, y admiré, como siempre, su capacidad crítica, su sentido de la dignidad personal, su aquilatado orgullo intelectual...

Somos muchos los que pensamos que la Universidad de Oviedo ha perdido a uno de sus mejores hijos. Esperamos que su pérdida lo sea solo física y no implique la de los valores que Santiago Melón Fernández encarnó.

\section{Bibliografía de Santiago Melón Fernández}

- Un capítulo en la historia de la Universidad de Oviedo (1883-1910), Oviedo, Instituto de Estudios Asturianos, 1963.

- «Noticia de un drama inédito», en Boletín del Instituto de Estudios Asturianos, XXI, nº 62 (1967), págs. 149-156.

- «Sobre H. Marcuse y nuestro tiempo», en Archivum, XVIII (1968), págs. 233-251.

— «Sobre la sociología de Emilio Durkheim», en Archivum, XXI (1971), págs. 207-304.

— «Introducción» a Poesía (en bable) de F. Fernández Quevedo, Oviedo, Instituto de Estudios Asturianos, págs. 7-28. 
— «Los dos últimos siglos», en El libro de Oviedo, Oviedo, ed. Naranco, 1974, págs. 63-87.

— «Notas sobre Quatrevingt-treize», en Archivum, XXVI (1976), págs. 103-115.

- «Campoamor ideólogo», en Estudios ofrecidos a Emilio Alarcos Llorach (con motivo de sus XXV años de docencia en la Universidad de Oviedo), Oviedo, Universidad de Oviedo, tomo III, 1978, págs. 435-457.

- «La generación del Carbayón y la Revista de Asturias», en Los Cuadernos del Norte, II, no 7 (1981), págs. 104-108.

- «Algunos aspectos cuantitativos del Viaje de Turquía», en Los Cuadernos del Norte, IV, no 22 (1983), págs. 16-24.

— «Notas sobre la revolución de 1820 en Asturias», en Ástura, I (1983), págs. 43-48.

- «La Extensión Universitaria: antecedentes y características», en Clarín y La Regenta en su tiempo (Actas del Simposium internacional del centenario de La Regenta), Oviedo, Consejería de Cultura-Universidad de OviedoAyuntamiento de Oviedo, 1984, págs. 93-110.

- Reseña de Periodismo e Ilustración en Manuel Rubín de Celis de I. Urzainqui y A. Ruiz de la Peña, en Ástura, 2 (1984), págs. 110-111.

- «Datos para la historia de la Universidad de Oviedo durante la guerra civil», en Ástura, 3 (1985), págs. 69-75.

- «Notas sobre la Rapsodia Económico Política Monárquica del Marqués de Santa Cruz», en Ástura, 4 (1985), págs. 86-89.

- «Prólogo» a la edición facsimilar de Historia de la Universidad de Oviedo de Fermín Canella Secades, Oviedo, Universidad de Oviedo, 1985, págs. VII-XIX.

- El viaje a América del Profesor Altamira, Oviedo, Universidad de Oviedo, 1987.

- «Las grandes etapas del hispanoamericanismo. El Movimiento de Oviedo», en Ástura, 9 (1993), págs. 115-122.

- «Semblanza biográfica del Dr. Antonio García Oliveros», en Boletín del Instituto de Estudios Asturianos, XLIX, no 146 (1995), págs. 615-629.

- «Unas palabras sobre Jovellanos», en Estudios Dieciochistas en Homenaje al Profesor José Miguel Caso González, tomo II, Oviedo, Instituto Feijoo de Estudios del Siglo XVIII-Caja de Asturias, 1995, págs. 105-110.

- «Prólogo» a Ramón Pérez de Ayala testigo de su tiempo de F. Friera Suárez, Gijón, Fundación Alvargonzález, 1997, págs. 2-19.

- Estudios sobre la Universidad de Oviedo, Oviedo, Universidad de Oviedo, 1998.

- «El conflicto universitario de 1884 en Oviedo», en Estudios sobre la Universidad de Oviedo, Oviedo, Universidad de Oviedo, (1998), págs. 177-204.

- «Restauración y desastre», en la revista Clarín, no extraordinario, Oviedo, (1998), págs. 177-204. 
— «Regeneracionismo y movimiento georgista en España», en Revista Asturiana de Economía, no 14 (1999), págs. 279-289.

- «Félix de Aramburu y Zuloaga», en Homenaje a José María Martínez Cachero, Oviedo, Universidad de Oviedo, tomo III, 2000, págs. 209-225. 